\title{
Efficacy of Low-dose Intravenous Ketamine vs Intravenous Tramadol Infusion for Postcesarean Section Analgesia following Spinal Anesthesia: A Prospective, Randomized, Double-blinded Clinical Study
}

\author{
${ }^{1}$ Surendra K Sethi, ${ }^{2}$ Neena Jain, ${ }^{3}$ Kavita Jain, ${ }^{4}$ Beena Thada
}

\begin{abstract}
Background: Postoperative pain is of greatest concern in parturients undergoing cesarean section. Low-dose intravenous (IV) ketamine infusion has been considered to be an effective postoperative analgesia and resurged again as a substitute of opioid analgesics. This study aims to evaluate the efficacy of low dose iv ketamine versus iv tramadol infusion in reducing postoperative pain and rescue analgesic requirements.
\end{abstract}

Materials and methods: This prospective study was conducted on 150 parturients with American Society of Anesthesiologists (ASA) grades I and II, aged 18 to 35 years scheduled to undergo elective or emergency cesarean section under regional anesthesia. All the parturients were randomly allocated into three groups of 50 patients each. Group C (control group) received $5 \mathrm{~mL}$ saline; group $\mathrm{K}$ (ketamine group) received $5 \mathrm{~mL}$ of ketamine ( $0.05 \mathrm{mg} / \mathrm{kg} /$ hour); and group T (tramadol group) received $5 \mathrm{~mL}$ of tramadol (120 mg/24 hours) in $500 \mathrm{~mL}$ of Ringer's lactate. Tramadol ( $1 \mathrm{mg} / \mathrm{kg}$ ) was given as rescue analgesic. Pain scores, patient satisfaction scores, time to first demand of rescue analgesic, the total number of doses, and total consumption of rescue analgesic along with side effects were recorded.

Results: The cumulative visual analog scale (VAS) noted at rest, cough, and movement was significantly less in groups $\mathrm{K}$ and $\mathrm{T}$ as compared with group $C(p<0.001)$. The time of requirement of first rescue analgesic dose was significantly prolonged in group K $(6.17 \pm 3.05$ hours $)$ and group $T(4.04 \pm 1.26$ hours $)$ as compared with group $C(2.16 \pm 0.84$ hours $)(p<0.001)$. The total number of doses of rescue analgesic given in 24 and 48 hours was significantly decreased in groups $\mathrm{K}$ and $\mathrm{T}$ as compared with group $C(p<0.001)$. The satisfaction scores were significantly better in groups $K$ and $T(p<0.001)$.

Conclusion: We concluded that low-dose IV ketamine infusion was associated with significantly lower pain scores, reduced rescue analgesic requirement along with better patient satisfaction so that it could be used as a useful adjunct to multimodal postoperative analgesia.

${ }^{1,4}$ Assistant Professor, ${ }^{2}$ Senior Professor and Head, ${ }^{3}$ Senior Professor

${ }^{1-4}$ Department of Anesthesiology, Jawaharlal Nehru Medical College and Associated Hospitals, Ajmer, Rajasthan, India

Corresponding Author: Surendra K Sethi, Assistant Professor Department of Anesthesiology, Jawaharlal Nehru Medical College and Associated Hospitals, Ajmer, Rajasthan, India Phone: +919587150598, e-mail: drsurendrasethi80@gmail.com
Keywords: Analgesia, Cesarean section, Ketamine, Postoperative, Spinal anesthesia, Tramadol.

How to cite this article: Sethi SK, Jain N, Jain K, Thada B. Efficacy of Low-dose Intravenous Ketamine vs Intravenous Tramadol Infusion for Postcesarean Section Analgesia following Spinal Anesthesia: A Prospective, Randomized, Double-blinded Clinical Study. Res Inno in Anesth 2018;3(1):1-7.

Source of support: Nil

Conflict of interest: None

\section{BACKGROUND}

Postoperative pain is the most undesirable feature and is of great concern in the parturients undergoing cesarean section. Pain impairs the mother's ability to take optimal care of her newborn child as well as reduce the ability to breast-feed effectively in the immediate postoperative period. So adequate management of postoperative pain is required, which allows early ambulation and postoperative rehabilitation after cesarean section. The goals of postcesarean pain management include minimal pain at rest and movement, patient satisfaction along with minimal maternal and neonatal side effects. ${ }^{1-3}$

Opioids are commonly used for postoperative pain relief; however, these are associated with various undesirable side effects, including acute tolerance, sedation, respiratory depression, nausea, and vomiting. Tramadol is an atypical centrally acting, potent opioid analgesic, which acts as an opioid agonist as well as a serotonin and noradrenaline reuptake inhibitor. However, it has minimal risk of respiratory depression with preserved hypoxic ventilatory response and limited effect on gastrointestinal function. The IV infusion of tramadol has an advantage of producing predictable blood levels, thereby reducing the associated adverse effects simultaneously preserving or enhancing the analgesic efficacy. ${ }^{4-6}$

Ketamine, an N-methyl-D-aspartate (NMDA) antagonist, inhibits central pain sensitization at subanesthetic doses, and various studies have been undertaken to support the role of low-dose ketamine as an analgesic adjunct for postoperative pain relief after cesarean section. The low-dose IV infusion has been considered an effective 
method for postoperative ketamine administration possessing both centrally mediated analgesic properties with minimal effect on consciousness and cognition, which is desirable for these patients. ${ }^{7-9}$

So we hypothesized that analgesic adjuvants, such as NMDA antagonists like ketamine may play a significant role in improving the analgesic efficacy of traditional opioid-based technique of postoperative pain management after cesarean delivery simultaneously decreasing their associated side effects by reducing rescue opioid analgesic requirement. This prospective randomized study was conducted to evaluate the efficacy of low-dose IV ketamine vs IV tramadol infusion over 24 hours in reducing postoperative pain and rescue analgesic requirements.

\section{MATERIALS AND METHODS}

After obtaining approval from the local Institutional Ethical Committee and written informed consent from all the parturients, this prospective randomized doubleblind study was conducted on 150 parturients, ASA grades I and II, aged 18 to 35 years, scheduled to undergo elective or emergency cesarean section under regional anesthesia. The parturients with a history of allergy to nonsteroidal anti-inflammatory drugs (NSAIDs) or any study drugs, bleeding tendency, bronchial asthma, peptic ulcer disease, liver disease, kidney disease, patients on anticoagulants, patient with psychological disorders, patients who denied the regional anesthetic technique, or patients who had required a conversion to general anesthesia due to inadequate neuraxial block were excluded from our study.

All the parturients were randomly allocated into three groups of 50 patients each, including group C (control group), group $\mathrm{K}$ (ketamine group), and group $\mathrm{T}$ (tramadol group) using computer-generated random number tables and sealed envelope technique for concealment.

After arrival of the patient in the operating room, a thorough preanesthetic evaluation was done, and written and informed consent was obtained. Standard monitoring including oxygen saturation, noninvasive blood pressure, electrocardiogram, and baseline vital parameters were recorded. A 18G IV cannula was secured and Ringer's lactate was started to preload the patient before spinal anesthesia. After preloading with $500 \mathrm{~mL}$ of fluid, all the patients were given spinal anesthesia with $0.5 \%$ hyperbaric bupivacaine $(10 \mathrm{mg})$ using 25G spinal needle in L3-4 space by midline approach to achieve an appropriate level of analgesia (T4-T6). Oxytocin (15 U) was given as IV infusion to all patients after the delivery of baby. Diclofenac suppositories (100 mg) were given to all patients after wound dressing on the operation table.
All the three groups received infusions up to 24 hours postoperatively, which was started on the operation theater table immediately after wound dressing by a separate IV line. Group C received $5 \mathrm{~mL}$ saline in $500 \mathrm{~mL}$ of Ringer's lactate; group $\mathrm{K}$ received $5 \mathrm{~mL}$ (estimated dose) of ketamine $(0.05 \mathrm{mg} / \mathrm{kg} /$ hour $)$ in $500 \mathrm{~mL}$ of Ringer's lactate; and group $\mathrm{T}$ received $5 \mathrm{~mL}$ (estimated dose) of tramadol $(120 \mathrm{mg} / 24$ hours) in $500 \mathrm{~mL}$ of Ringer's lactate. The diclofenac suppositories $(100 \mathrm{mg}$ ) were repeated in all the patients at $12,24,36$, and 48 hours postoperatively. Injection tramadol $1 \mathrm{mg} / \mathrm{kg}$ IV was given as rescue analgesic for breakthrough pain on patient's demand or if the VAS score was $\geq 30$ at rest for the next 48 hours. No other NSAIDs were permitted in this period.

The anesthesiologist who recorded the postoperative parameters was blinded to the study group to maintain the double blinding of the study. The vital parameters including pulse rate (PR), systolic blood pressure (SBP), diastolic blood pressure (DBP), and respiratory rate (RR) were recorded both preoperatively and postoperatively at $0,1,2,3,4,6,12,24,36$, and 48 hours. The assessment of pain intensity was done using VAS ranging from $0 \mathrm{~mm}$ (no pain) to $100 \mathrm{~mm}$ (worst pain). The VAS was noted at 0 , $1,2,3,4,6,12,24,36$, and 48 hours for pain at rest, cough, and movement. The time to first demand of rescue analgesic and the total number of rescue analgesic doses were recorded initially up to 24 hours until the stopping of infusions in the postoperative period and then consecutively in next 24 hours. The total consumption of rescue analgesic was also noted in each group separately. The satisfaction score was also estimated using a VAS (0-100) at 24 and 48 hours postoperatively, which was graded as: 0 to 25 : excellent; 25 to 50: good; 50 to 75 : fair; and 75 to 100: poor. Any side effects like nausea or vomiting, pruritus, drowsiness, hallucination, respiratory depression were noted and if patient had vomiting, ondansetron $4 \mathrm{mg}$ IV was given.

\section{Statistical Analysis}

A sample size of 50 patients in each group was calculated based on the estimation that this sample size would be able to detect a $30 \%$ reduction in the dose of postoperative opioids used in both ketamine and tramadol groups compared with the control group with $80 \%$ power and type I error of 0.05 . The demographic data, pain score, satisfaction score, and total rescue analgesic consumption were analyzed using one-way analysis of variance. For multiple comparison between the groups, Student's paired " $\mathrm{t}$ " test was used. The chi-square test was used to analyze the side effects. Statistical analysis was performed using Statistical Package for the Social Sciences software version 10.0. The data were expressed as mean value \pm standard deviation and number (percentage); $\mathrm{p} \leq 0.05$ 
was considered statistically significant and $\mathrm{p}<0.001$ was considered highly significant.

\section{RESULTS}

All the three groups were comparable with respect to demographic data, including mean age, mean weight, mean height, and ASA grade along with duration of surgery $(p>0.05)$ (Table 1$)$.

The cumulative VAS noted at rest, cough, and movement was significantly less in groups $\mathrm{K}$ and $\mathrm{T}$ as compared with group $C(p<0.001)$. However, when group $K$ was compared with group $\mathrm{T}$, cumulative VAS was significantly less in group K $(\mathrm{p}<0.001)$. At all time intervals, VAS at movement in group $\mathrm{K}$ remained $<30$, while in groups $\mathrm{T}$ and $\mathrm{C}, \mathrm{VAS}$ remained $\geq 30$ at 3 to 12 and 2 to 24 hours respectively (Table 2).

The time of requirement of first rescue analgesic dose was significantly prolonged in group $\mathrm{K}(6.17 \pm 3.05$ hours $)$ and group $\mathrm{T}$ ( $4.04 \pm 1.26$ hours) as compared with group
C $(2.16 \pm 0.84$ hours $)(p<0.001)$. The total number of doses of rescue analgesic given in 24 and 48 hours was significantly lesser in groups $\mathrm{K}$ and $\mathrm{T}$ as compared with group $C(p<0.001)$. Similarly, the total dose of rescue analgesic given was also significantly lesser in group $\mathrm{K}$ $(161.40 \pm 47.82 \mathrm{mg})$ and group $\mathrm{T}(103.64 \pm 37.15 \mathrm{mg})$ when compared with group C $(73.30 \pm 29.66 \mathrm{mg})(\mathrm{p}<0.001)$. Time to requirement of first dose of rescue analgesic was significantly prolonged in group $\mathrm{K}$ as also total number of rescue analgesic in 24 and 48 hours along with total dose of rescue analgesic consumption was significantly lesser in group K as compared with group $\mathrm{T}(\mathrm{p}<0.001)$ (Table 3$)$.

In all the three groups, the majority of the patients had nausea and vomiting (T $80 \%, \mathrm{C} 48 \%$, and $\mathrm{K} 44 \%$ ), all of whom had received ondansetron as treatment. In group $C$, $28(56 \%)$ patients were unable to breast-feed due to pain as compared with 4 ( $8 \%$ ) in group K and 14 (28\%) in group T (Table 4). The satisfaction score observed in group $\mathrm{K}$ was significantly better than group $\mathrm{T}$, which was significantly

Table 1: Demographic data and duration of surgery

\begin{tabular}{lllll}
\hline Parameters & Group C $(n=50)$ & Group $K(n=50)$ & Group $T(n=50)$ & $p$-value \\
\hline Age (years) & $25.72 \pm 3.40$ & $26.48 \pm 3.07$ & $24.24 \pm 2.97$ & 0.052 \\
Weight $(\mathrm{kg})$ & $56.52 \pm 10.15$ & $56.24 \pm 7.96$ & $55.84 \pm 5.85$ & 0.080 \\
Height $(\mathrm{cm})$ & $155.28 \pm 2.33$ & $154.88 \pm 2.69$ & $154.60 \pm 2.10$ & 0.360 \\
ASA grade I/II & $40 / 10$ & $40 / 10$ & $44 / 6$ & 0.475 \\
$\mathrm{n} /(\%)$ & $80 / 20$ & $80 / 20$ & $88 / 12$ & \\
Duration of surgery (min) & $50.40 \pm 8.68$ & $48.20 \pm 10.18$ & $55.20 \pm 8.27$ & 0.064 \\
\hline
\end{tabular}

$p>0.05$, not significant; data expressed as mean \pm standard deviation and number (percentage)

Table 2: Comparison of cumulative VAS $(0-100 \mathrm{~mm})$ between groups

\begin{tabular}{|c|c|c|c|c|c|c|}
\hline \multirow[b]{2}{*}{ Time (hours) } & \multirow[b]{2}{*}{ Group C $(n=50)$} & \multirow[b]{2}{*}{ Group $K(n=50)$} & \multirow[b]{2}{*}{ Group $T(n=50)$} & \multicolumn{3}{|c|}{$p$-value } \\
\hline & & & & $C / K$ & $K / T$ & $C / T$ \\
\hline Rest & $17.79 \pm 14.73$ & $9.62 \pm 10.11$ & $15.06 \pm 13.32$ & $<0.001$ & $<0.001$ & $<0.001$ \\
\hline Cough & $29.83 \pm 18.21$ & $14.88 \pm 11.95$ & $21.42 \pm 16.36$ & $<0.001$ & $<0.001$ & $<0.001$ \\
\hline Movement & $29.80 \pm 19.21$ & $15.76 \pm 12.58$ & $24.90 \pm 19.39$ & $<0.001$ & $<0.001$ & $<0.001$ \\
\hline
\end{tabular}

$\mathrm{p}<0.001$, highly significant; data expressed as mean \pm standard deviation

Table 3: Comparison of rescue analgesic requirement between the three groups

\begin{tabular}{|c|c|c|c|c|c|c|}
\hline \multirow[b]{2}{*}{ Rescue analgesic requirement } & \multirow[b]{2}{*}{ Group C $(n=50)$} & \multirow[b]{2}{*}{ Group K $(n=50)$} & \multirow[b]{2}{*}{ Group $T(n=50)$} & \multicolumn{3}{|c|}{ p-value } \\
\hline & & & & $C / K$ & $K / T$ & $C / T$ \\
\hline Time of 1st dose of rescue analgesic (hrs) & $2.16 \pm 0.84$ & $6.17 \pm 3.05$ & $4.04 \pm 1.26$ & $<0.001$ & $<0.001$ & $<0.001$ \\
\hline Total number of doses in $1 \mathrm{st} 24 \mathrm{hrs}$ & $2.68 \pm 0.79$ & $1.30 \pm 0.47$ & $1.84 \pm 0.62$ & $<0.001$ & $<0.001$ & $<0.001$ \\
\hline Total number of doses in $48 \mathrm{hrs}$ & $2.80 \pm 0.81$ & $1.30 \pm 0.47$ & $1.84 \pm 0.62$ & $<0.001$ & $<0.001$ & $<0.001$ \\
\hline Total dose of rescue analgesic given (mg) & $161.40 \pm 47.82$ & $73.30 \pm 29.66$ & $103.64 \pm 37.15$ & $<0.001$ & $<0.001$ & $<0.001$ \\
\hline
\end{tabular}

$\mathrm{p}<0.001$, highly significant; data expressed as mean \pm standard deviation

Table 4: Comparison of postoperative side effects between the three groups

\begin{tabular}{llll}
\hline Side effects & Group C $(n=50)$ & Group K $(n=50)$ & Group T(n=50) \\
\hline Pruritus & $0(0)$ & $0(0)$ & $2(4)$ \\
Nausea/vomiting & $24(48)$ & $22(44)$ & $40(80)$ \\
Drowsiness & $0(0)$ & $2(4)$ & $2(4)$ \\
Hallucination & $0(0)$ & $4(8)$ & $0(0)$ \\
Resp. depression & $0(0)$ & $0(0)$ & $0(0)$ \\
Failure to breast-feed due to pain & $28(56)$ & $4(8)$ & $14(28)$ \\
\hline
\end{tabular}

Data expressed as number (percentage) 
Table 5: Comparison of mean satisfaction score $(0-100 \mathrm{~mm})$ in three groups

\begin{tabular}{|c|c|c|c|c|c|c|}
\hline \multirow[b]{2}{*}{ Time (hrs) } & \multirow[b]{2}{*}{ Group C $(n=50)$} & \multirow[b]{2}{*}{ Group $K(n=50)$} & \multirow[b]{2}{*}{ Group $T(n=50)$} & \multicolumn{3}{|c|}{$p$-value } \\
\hline & & & & $C / K$ & $K / T$ & $\mathrm{C} / \mathrm{T}$ \\
\hline Satisfaction score at $24 \mathrm{hrs}$ & $59.60 \pm 11.60$ & $38.00 \pm 9.90$ & $52.80 \pm 8.82$ & $<0.001$ & $<0.001$ & $<0.01$ \\
\hline Satisfaction score at $48 \mathrm{hrs}$ & $46.00 \pm 9.90$ & $30.00 \pm 0.00$ & $41.20 \pm 10.03$ & $<0.001$ & $<0.001$ & $<0.05$ \\
\hline
\end{tabular}

$p<0.05$, significant; $p<0.001$, highly significant; data expressed as mean \pm standard deviation

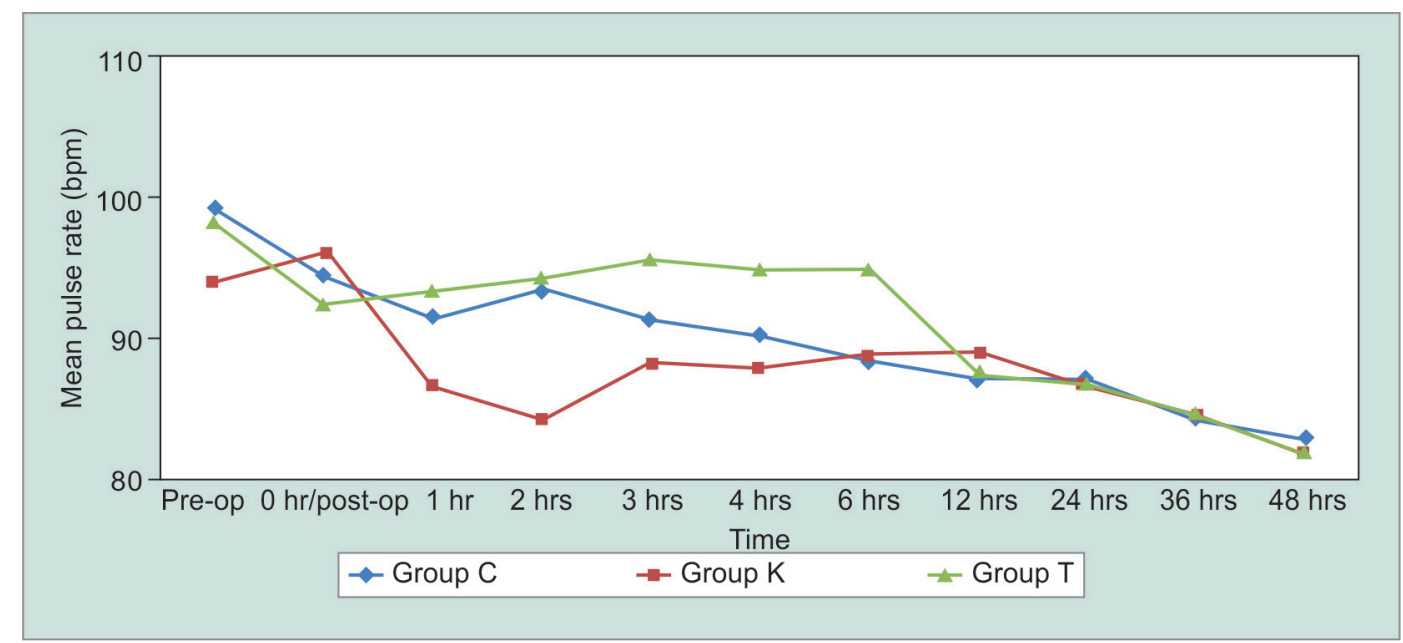

Graph 1: Comparison of mean PR (beats per min) at different time intervals between the groups

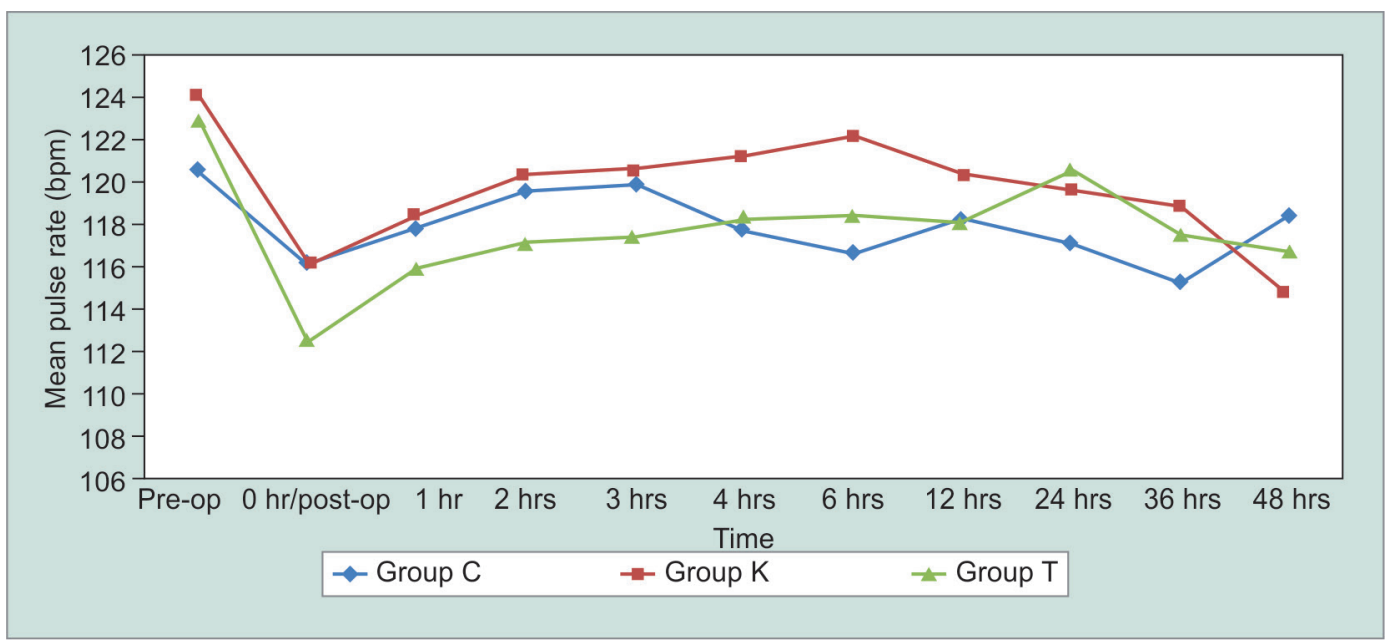

Graph 2: Comparison of mean SBP $(\mathrm{mm} \mathrm{Hg})$ at different time intervals between the groups

better than group C at 24 and 48 hours postoperatively. At 24 hours, the satisfaction scores were "good" in group $\mathrm{K}$ compared with groups $\mathrm{T}$ and $\mathrm{C}$ (fair) (Table 5).

The various vital parameters including PR, SBP, DBP, and $R R$ recorded postoperatively at $0,1,2,3,4,6,12,24$, 36 , and 48 hours were found to be statistically insignificant at all time intervals ( $\mathrm{p}>0.05)$ (Graphs 1 to 4 ).

\section{DISCUSSION}

The primary concern of our study was to avoid opioidrelated side effects by reducing additional rescue opioid analgesic requirements along with providing superior analgesia using multimodal approach based on the recognition of alternative analgesic receptors. So the systemic use of ketamine, an NMDA receptor antagonist, given as low-dose IV infusion modulates the receptors mediating analgesia. In the present study, the multimodal approach for postoperative analgesia was followed by using diclofenac suppository, tramadol or ketamine infusion, and tramadol as rescue analgesic if required. ${ }^{10,11}$

In our study, the cumulative VAS at rest was $<30$ in all the three groups, indicating adequate postoperative analgesia at rest in all patients. Similarly, the VAS at cough and movement was $<30$ in patients of group $\mathrm{K}$ during first 48 hours; however, the patients in groups $\mathrm{T}$ and $\mathrm{C}$ had pain, i.e., VAS $>30$ on cough and movement during 


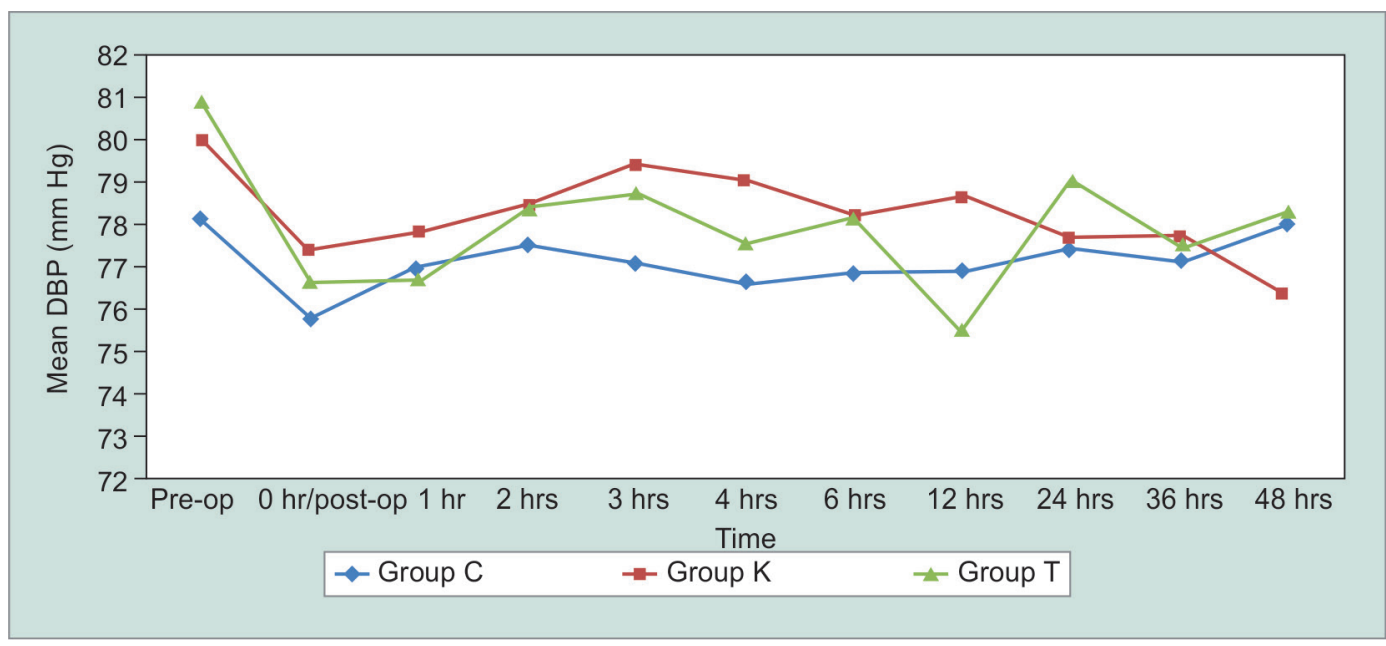

Graph 3: Comparison of mean DBP $(\mathrm{mm} \mathrm{Hg})$ at different time intervals between the groups

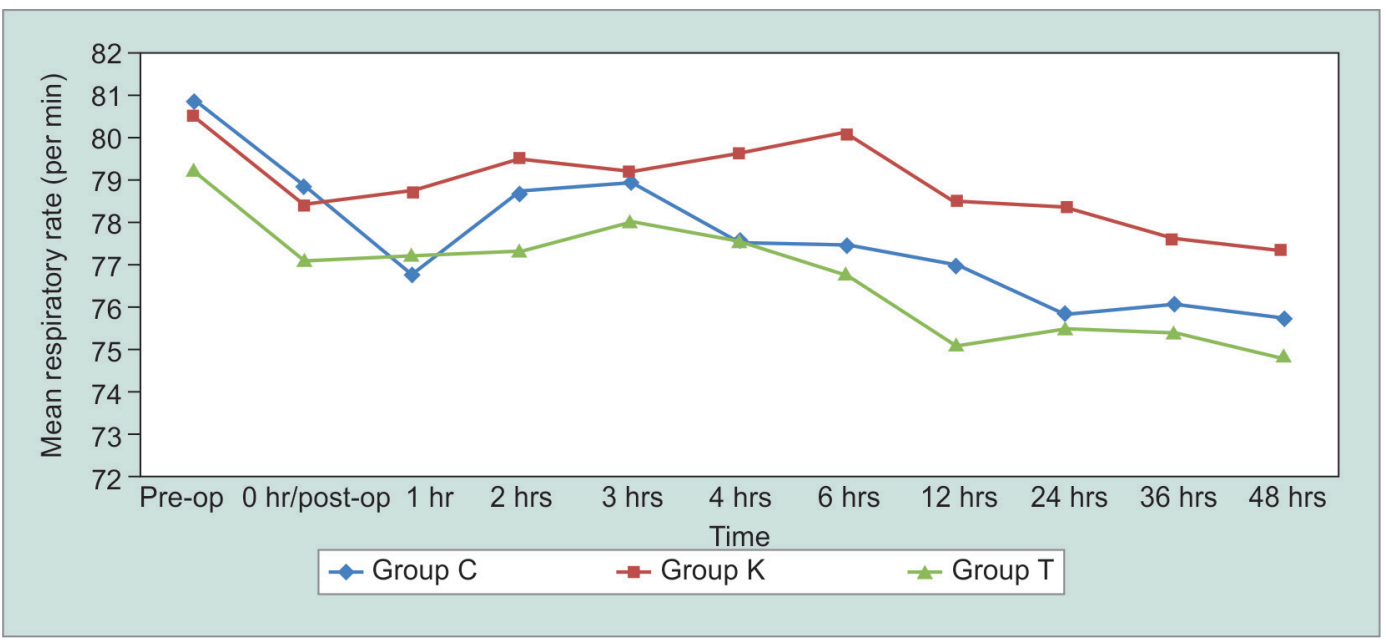

Graph 4: Comparison of mean RR (per min) at different time intervals between the groups

initial 3 to 12 hours and 2 to 24 hours respectively, that was statistically significant. Similar to our study, Adriaenssens et $\mathrm{al}^{12}$ compared ketamine infusion $(2.5 \mu \mathrm{g} / \mathrm{kg} / \mathrm{min})$ with saline infusion for postoperative analgesia up to 48 hours and found VAS scores significantly less in ketamine group as compared with control group. Guillou et $\mathrm{al}^{13}$ reported that VAS remained lower in ketamine infusion group as compared with placebo group at all time intervals of 48 hours study period but found to be statistically significant only at 16 and 44 hours at rest and 16, 20, and 40 hours at mobilization. However, the overall VAS scores were lower in ketamine infusion group. Unlugenc et $\mathrm{al}^{14}$ found significantly lower VAS scores in tramadol/ ketamine group when compared with tramadol group for analgesia. Rahmanian et $\mathrm{al}^{15}$ compared ketamine group with control group for postoperative analgesia and found significantly lower pain scores in ketamine group at 1, 2, 6, and 12 hours following surgery. Sen et $\mathrm{al}^{16}$ reported significantly lower postoperative pain scores in cesarean section patients who received low-dose ketamine infusion than who received normal saline. In contrast to our results, Han et $\mathrm{al}^{19}$ found no significant difference between ketamine and control groups for VAS scores at 2, 6, 12, and 24 hours postoperatively. This may be attributed to the use of fentanyl as rescue analgesic by patient-controlled analgesia (PCA) device at regular intervals in both groups.

Sen et $\mathrm{al}^{16}$ administered low-dose IV ketamine infusion after subarachnoid block, and on comparison with normal saline group, they found that the time to first analgesic requirement was significantly longer in ketamine group (197 vs 144 minutes). Similarly, the analgesic requirements during first 24 hours were significantly lower in ketamine group; however, there was no significant difference noted in subsequent 24 hours. Ghazi Saidi and Hajipour ${ }^{17}$ used preemptive low-dose ketamine prior to induction of general anesthesia and the time to first rescue analgesic requirement was significantly longer in ketamine group along with reduced mean dose of morphine consumption. Both of these studies indirectly support our assumption that ketamine in low doses can be used as a part of multimodal approach to provide better 
postoperative analgesia. ${ }^{16,17}$ The postoperative tramadol infusion has been found to reduce the rescue analgesic requirement by Webb et $\mathrm{al}^{18}$ who found mean PCA morphine consumption significantly lesser in tramadol group as compared with control group up to 48 hours as we found in our study too. Rahmanian et $\mathrm{al}^{15}$ also found significant difference between the two groups in terms of time to first rescue analgesic requirement as well as mean number of doses of rescue analgesic required postoperatively. ${ }^{15}$ However, Han et al ${ }^{19}$ found no significant difference in cumulative dose of fentanyl required in ketamine group except at 2 hours after surgery.

The present study highlights that patients who received ketamine infusion had better analgesia at rest, cough, and movement as compared with both tramadol and control groups. This is supported by lesser VAS scores, delayed requirement of rescue analgesic, and reduced total rescue analgesic consumption in ketamine group. This could be attributed to different mechanisms and site of action of ketamine. ${ }^{1,2}$ Lower dose of ketamine is associated with minimal physiological impact with low incidence of mild psychomimetic symptoms along with nystagmus and diplopia, improved pain scores along with reduced perioperative opioid analgesic consumption, and minimal side effects. ${ }^{1,2,20}$ Tramadol, in the present study, also showed better pain scores when compared with control group but associated with opioidrelated side effects. ${ }^{21,22}$

In our study, due to better pain relief in patients of ketamine group, the satisfaction scores were found to be better in group $\mathrm{K}$ as compared with groups T and C. Pirim et $\mathrm{al}^{23}$ compared ketamine infusion with saline infusion in patients scheduled for total abdominal hysterectomy and showed that mean satisfaction scores were better in the 24th and 48th hours in ketamine group and was statistically significant. Webb et $\mathrm{al}^{18}$ found association of tramadol infusion with improved analgesic efficacy and patient satisfaction as compared with control group.

In our study, nausea and vomiting was the only side effect which was most common in all three groups, with maximum incidence in group $\mathrm{T}(80 \%)$ as compared with both groups $\mathrm{K}$ and $\mathrm{C}$. The incidence of other side effects (pruritus, drowsiness, hallucination and respiratory depression) was less in all the three groups. Only four patients had hallucination in group K. Adriaenssens et $\mathrm{al}^{12}{ }^{12}$ Webb et al, ${ }^{18}$ and Unlugenc et $\mathrm{al}^{14}$ also reported the absence of hallucinations after low-dose ketamine infusion in their studies. This may be attributed to low-dose ketamine infusion as the hallucinations are usually seen with higher doses of ketamine. ${ }^{20}$ No respiratory depression was observed in any patient in all three groups, which was also similar to these studies. Pruritus was seen only in two patients of tramadol group which is an unwanted side effect of opioids. However, other studies done by Webb et $\mathrm{al}^{18}{ }^{18}$ Unlugenc et al, ${ }^{14}$ and Adriaenssens et $\mathrm{al}^{12}$ did not report any incidence of pruritus. In our study, the incidence of nausea and vomiting was comparable in groups $\mathrm{K}$ and C. Similarly, Unlugenc et al, ${ }^{14}$ Sen et $\mathrm{al}^{16}$ and Webb et $\mathrm{al}^{18}$ found no significant difference in the incidence of nausea and vomiting between ketamine and control groups. The various vital parameters remained in clinically acceptable range throughout the whole postoperative period.

As far as limitations of our study are concerned, the effect of postcesarean ketamine infusion on newborns of breast-feeding mothers was not measured. However, we have used low-dose ketamine infusion which might not have clinically significant effect on the developing brain of newborns as the neurotoxic effect of ketamine has been observed in animal studies in which higher doses of ketamine were administered for prolonged durations. Similarly, different results might have been observed with different doses of ketamine as well as type of anesthesia and duration of infusion. So further studies on ketamine as a postoperative analgesic must be done extensively while considering the above points to conclude its maximum clinical effect and safety along with minimal adverse effects.

\section{CONCLUSION}

We conclude that when low-dose IV ketamine infusion was used for postoperative analgesia there were significantly lower pain scores, reduced rescue analgesic requirement along with early ambulation, and better patient satisfaction scores as compared with tramadol and control groups. Although the patients who received tramadol infusion had better postoperative analgesia as compared with control group, they had more nausea and vomiting, delayed acceptance of fluids as well as delayed passage of flatus. So low-dose ketamine infusion could be used as a useful adjunct to multimodal postoperative analgesia with diclofenac and tramadol as rescue analgesic.

\section{REFERENCES}

1. Kerai S, Saxena KN, Taneja B. Post-caesarean analgesia: what is new? Indian J Anaesth 2017 Mar;61(3):200-214.

2. Schmid RL, Sandler AN, Katz J. Use and efficacy of low-dose ketamine in the management of acute postoperative pain: a review of current techniques and outcomes. Pain 1999 Aug;82(2):111-125

3. Ismail S, Afshan G, Monem A, Ahmed A. Postoperative analgesia following caesarean section: intravenous patient controlled analgesia versus conventional continuous infusion. Open J Anesthesiol 2012 Sep;2(4):120-126.

4. Ijichi K, Nijima K, Iwagaki T, Irie J, Uratsuji Y. A randomized double-blind comparison of epidural versus intravenous 
tramadol infusion for postoperative analgesia. Masui 2005 Jun;54(6):615-621.

5. Jellinek H, Haumer H, Grubhofer G, Klappacher G, Jenny T, Weindlmayr-Goettel M, Fitzal S. Tramadol in postoperative pain therapy. Patient-controlled analgesia versus continuous infusion. Anaesthesist 1990 Oct;39(10):513-520.

6. Gadsden J, Hart S, Santos AC. Post-cesarean delivery analgesia. Anesth Analg 2005 Nov;101(5 Suppl):S62-S69.

7. Helmy N, Badawy AA, Hussein M, Reda H. Comparison of the preemptive analgesia of low dose ketamine versus magnesium sulfate on parturient undergoing cesarean section under general anesthesia. Egypt J Anaesth 2015 Jan;31(1): 53-58.

8. Kaur S, Saroa R, Aggarwal S. Effect of intraoperative infusion of low-dose ketamine on management of postoperative analgesia. J Nat Sc Biol Med 2015 Jul-Dec;6(2):378-382.

9. Petrenko AB, Yamakura T, Baba $H$, Shimoji K. The role of N-methyl-D-aspartate (NMDA) receptors in pain: a review. Anesth Analg 2003 Oct;97(4):1108-1116.

10. Pan PH. Postcesarean delivery pain management: multimodal approach. Int J Obstet Anesth 2006 Jul;15(3):185-188.

11. Jolly AS, Jain P, Sood J. Ketamine-current uses and future perspectives. J Anaesthesiol Clin Pharmacol 2007 Apr;23(2):169-181.

12. Adriaenssens G, Vermeyen KM, Hoffmann VL, Mertens E, Adriaensen HF. Postoperative analgesia with i.v. patientcontrolled morphine: effect of adding ketamine. Br J Anaesth 1999 Sep;83(3):393-396.

13. Guillou N, Tanguy M, Seguin P, Branger B, Campion JP, Mallédant $Y$. The effects of small-dose ketamine on morphine consumption in surgical intensive care unit patients after major abdominal surgery. Anesth Analg 2003 Sep;97(3):843-847.

14. Unlugenc $\mathrm{H}$, Gunduz M, Ozalevli M, Akman H. Comparative study on the analgesic effect of tramadol, tramadol plus magnesium, and tramadol plus ketamine for postoperative pain management after major abdominal surgery. Acta Anaesthesiol Scand 2002 Sep;46(8):1025-1030.

15. Rahmanian M,Leysi M,HemmatiAA,Mirmohammadkhani M. The effect of low-dose intravenous ketamine on postoperative pain following cesarean section with spinal anesthesia: a randomized clinical trial. Oman Med J 2015 Jan;30(1):11-16.

16. Sen S, Ozmert G, Aydin ON, Baran N, Caliskan E. The persisting analgesic effect of low-dose intravenous ketamine after spinal anaesthesia for caesarean section. Eur J Anaesthesiol 2005 Jul;22(7):518-523.

17. Ghazi Saidi K, Hajipour A. Effects of preemptive Ketamine on post-cesarean analgesic requirement. Acta Med Iran 2002 Jun;40(2):100-103.

18. Webb AR,Skinner BS, LeongS, KolawoleH,Crofts T, Taverner M, Burn SJ. The addition of a small-dose ketamine infusion to tramadol for postoperative analgesia: a double-blinded, placebo-controlled, randomized trial after abdominal surgery. Anesth Analg 2007 Apr;104(4):912-917.

19. Han SY, Jin HC, Yang WD, Lee JH, Cho SH, Chae WS, Lee JS, Kim YI. The effect of low-dose ketamine on post-caesarean delivery analgesia after spinal anesthesia. Korean J Pain 2013 Jul;26(3):270-276.

20. Gorlin AW, Rosenfeld DM, Ramakrishna H. Intravenous subanesthetic ketamine for perioperative analgesia. J Anaesthesiol Clin Pharmacol 2016 Apr-Jun;32(2):160-167.

21. Rüd U, Fischer MV, Mewes R, Paravicini D. Postoperative analgesia with tramadol: Continuous infusion versus repetitive bolus administration. Anaesthesist 1994 May;43(5):316-321.

22. Chrubasik J, Buzina M, Schulte-Monting J, Attanassoff $P$, Alon E. Intravenous tramadol for postoperative pain: comparison of intermittent dose regimens with and without maintenance infusion. Eur J Anaesthesiol 1992 Jan;9(1):23-28.

23. Pirim A, Karaman S, Uyar M, Certu A. Addition of ketamine infusion to patient controlled analgesia with intravenous morphine after abdominal hysterectomy. Agri 2006 Jan;18(1):52-58. 